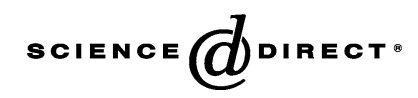

\title{
Processes and patterns in transitions and system innovations: Refining the co-evolutionary multi-level perspective
}

\author{
F.W. Geels* \\ Technical University Eindhoven, IPO 2.10, 5600 MB Eindhoven, The Netherlands
}

Received 15 March 2004; accepted 13 August 2004

\begin{abstract}
This article investigates transitions at the level of societal functions (e.g., transport, communication, housing). Societal functions are fulfilled by sociotechnical systems, which consist of a cluster of aligned elements, e.g., artifacts, knowledge, markets, regulation, cultural meaning, infrastructure, maintenance networks and supply networks. Transitions are conceptualised as system innovations, i.e., a change from one sociotechnical system to another. The article describes a co-evolutionary multi-level perspective to understand how system innovations come about through the interplay between technology and society. The article makes a new step as it further refines the multi-level perspective by distinguishing characteristic patterns: (a) two transition routes, (b) fit-stretch pattern, and (c) patterns in breakthrough.

(C) 2005 Elsevier Inc. All rights reserved.
\end{abstract}

Keywords: Transition; System innovation; Co-evolution; Multi-level perspective; Patterns

\section{Introduction}

This paper deals with transitions at the level of societal functions such as transportation, communication, housing, energy supply, feeding. Societal functions are fulfilled by sociotechnical systems, which consist of a cluster of elements, including technology, regulation, user practices and markets, cultural meaning, infrastructure, maintenance networks, and supply networks [1]. Fig. 1 gives

\footnotetext{
* Tel.: +31 402475414 .

E-mail address: f.w.geels@tm.tue.nl.
} 


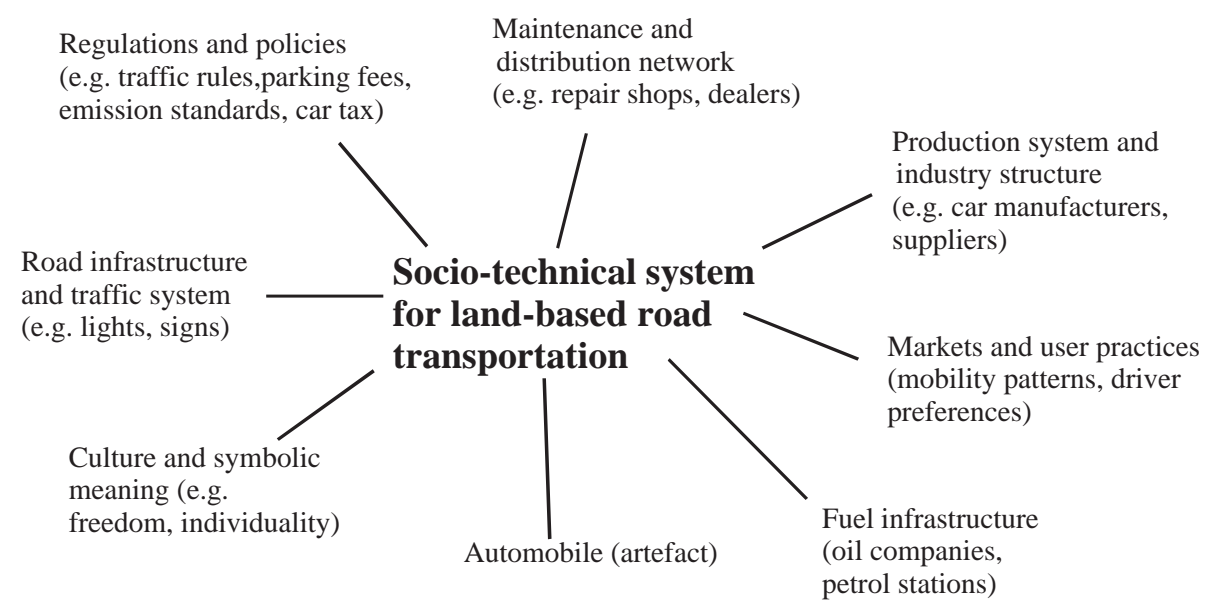

Fig. 1. Sociotechnical system for modern car-based transportation.

an example of a sociotechnical system for land-based road transportation. A transition is a shift from one sociotechnical system to another, i.e., a system innovation. System innovations are co-evolution processes, which involve technological changes, as well as changes in other elements.

In recent years, there is increasing interest in transitions and system innovation, because of their promise to achieve jumps in environmental efficiency. In transport systems, energy systems, agricultural systems etc., there are promising new technologies with better environmental performance. But many of these new technologies are not (yet) taken up. This is partly related to economic reasons, but also to social, cultural, infrastructural and regulative reasons. Because existing systems are 'locked in' at multiple dimensions, they are stable and not easy to change. Hence, the analytical focus in academic sustainability analyses has widened from artifacts to sociotechnical systems [2-5].

The topic of system innovation is taken up to some extent in the systems of innovation approach. Innovation systems can be defined on various levels, e.g., national, regional or sectoral systems of innovation. An important insight from the systems of innovation approach(es) is the emphasis on interlinkages between elements and co-evolutionary processes. But the main focus in the systems of innovation approach is on the functioning of systems rather than the change of systems (e.g., a static or comparative analysis of the innovative performance of countries). Hence, a recent review of the sectoral system of innovation approach [6] noted that one of the key questions that need to be explored is: how do new sectoral systems emerge, and what is the link with the previous sectoral system?

This paper addresses two questions. How do system innovations come about? Are there particular patterns in system innovations? Section 2 answers the first question, by describing the so-called multilevel perspective (MLP). The MLP has a focus on technology-in-context and emphasises co-evolution of technology and society. The second question is answered in Section 3. In that section, the MLP is further refined and 'filled in' with particular patterns in system innovations. These patterns are briefly illustrated with empirical anecdotes, based on three elaborate case studies: (a) the transition from propeller-piston engine aircraft to turbojets, (b) the transition from sailing ships to steamships, and (c) the transition in urban land transportation from horse-drawn carriages to automobiles. These case studies are described in detail elsewhere [7]. 


\section{Conceptual multi-level perspective}

The multi-level perspective (MLP) is outlined only briefly, because it has been described more elaborately elsewhere [1,5,7-12]. The MLP pragmatically uses insights from evolutionary economics, sociology of technology, history of technology and innovation studies. The MLP distinguishes three analytical and heuristic levels to understand system innovations.

The meso-level is formed by sociotechnical regimes. This concept builds upon the concept of technological regimes [13], but is wider in two respects. First, while Nelson and Winter refer to cognitive routines, Rip and Kemp widen the regime concept with the sociological category of 'rules:" "A technological regime is the rule-set or grammar embedded in a complex of engineering practices, production process technologies, product characteristics, skills and procedures, ways of handling relevant artefacts and persons, ways of defining problems; all of them embedded in institutions and infrastructures" ([10], p. 340). While the cognitive routines of Nelson and Winter are embedded in the minds of engineers, these rules are embedded more widely in the knowledge base, engineering practices, corporate governance structures, manufacturing processes and product characteristics. Second, sociotechnical regimes not only refer to the social group of engineers and firms, but also to other social groups. Sociotechnical systems are actively created and maintained by several social groups (see Fig. 2). Their activities reproduce the elements and linkages in sociotechnical systems. Because each of these social groups has its own distinctive features and its own 'selection' environment, they have relative autonomy. On the other hand, the groups are also interdependent and interacting with each other. Interdependence and linkage between sub-systems occur because activities of social groups are coordinated and aligned to each other. This is represented with the concept of sociotechnical regime (see [1] for more on the dynamic relationships between regimes and actors).

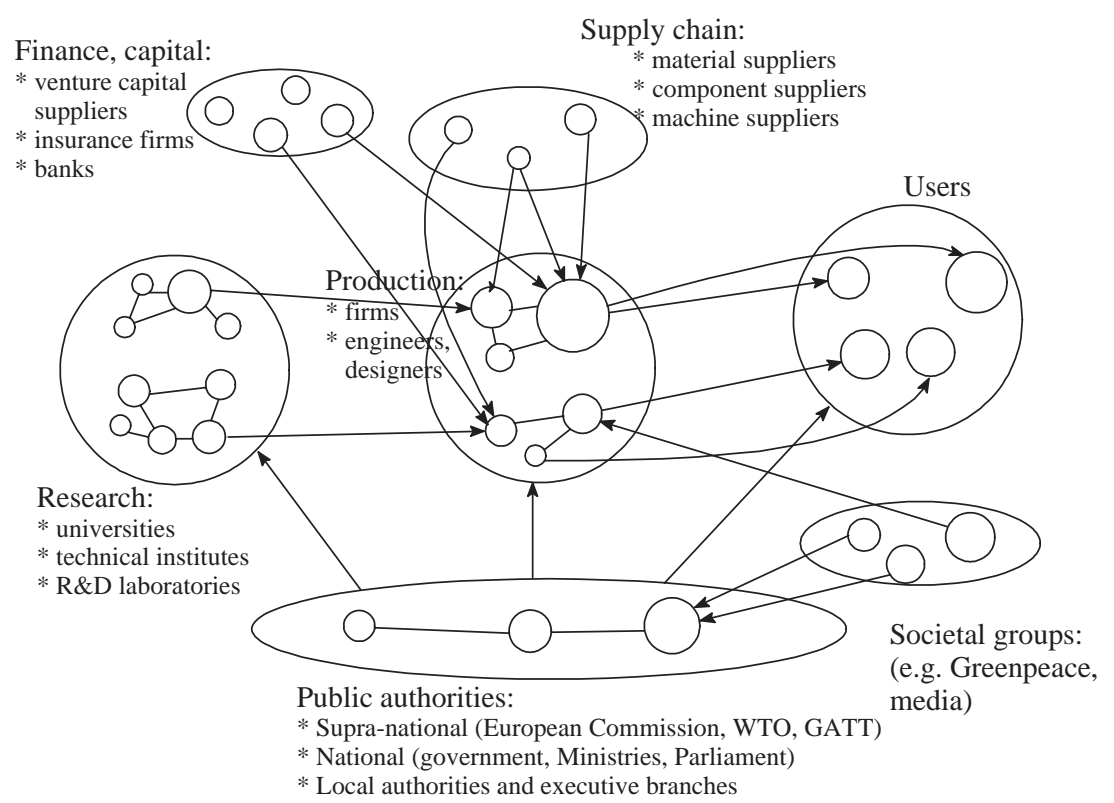

Fig. 2. Social groups which (re)produce sociotechnical systems ([12], p. 1260). 
By providing orientation and coordination to the activities of relevant actor groups, sociotechnical regimes account for the stability of sociotechnical systems. This stability is dynamic, meaning that innovation still occurs but is of an incremental nature, leading to 'technical trajectories' and path dependencies.

The micro-level is formed by technological niches, the locus for radical innovations ('variation'). Because the performance of radical novelties is initially low, they emerge in 'protected spaces,' which shield them from mainstream market selection. Niches thus act as 'incubation rooms' for radical novelties [14]. Niches are important, because they provide locations for learning processes. Learning processes occur on many dimensions, e.g., technology, user preferences, regulation, symbolic meaning, infrastructure, and production systems. Niches also provide space to build the social networks which support innovations, e.g., supply chains, user-producer relationships. These internal niche processes have been analysed and described under the heading of strategic niche management $[9,11,15,16]$.

The macro-level is formed by the sociotechnical landscape, which refers to aspects of the wider exogenous environment, which affect sociotechnical development (e.g., globalisation, environmental problems, cultural changes). The metaphor 'landscape' is used because of the literal connotation of relative 'hardness' and to include the material aspects of society, e.g., the material and spatial arrangements of cities, highways, and electricity infrastructures. Landscapes are beyond the direct influence of actors and cannot be changed at will.

The (socio)logic of the three levels is that they provide different kinds of coordination and structuration of activities in local practices. The relationship between the three concepts can be understood as a nested hierarchy, meaning that regimes are embedded within landscapes and niches within regimes (see Fig. 3). The work in niches is often geared to the problems of existing regimes (hence, the arrows in the figure). Actors support the niche hoping that novelties will eventually be used in the regime or even replace it. This is not easy, however, because the existing regime is entrenched in many ways (e.g., institutionally, organisationally, economically, culturally). Radical novelties often have a mis-match with the existing regime and do not easily break through. Nevertheless, niches are crucial for system innovations, because they provide the seeds for change.

The key point is that system innovations come about through the interplay between dynamics at multiple levels. Several phases can be distinguished in transitions [17]. In the first phase, novelties

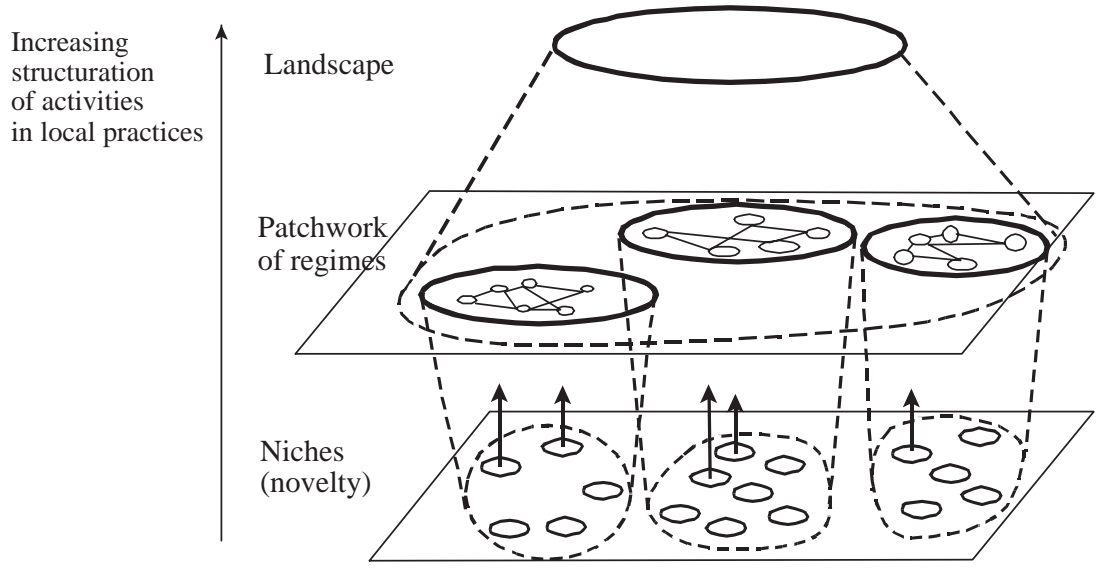

Fig. 3. Multiple levels as a nested hierarchy ([12], p. 1261). 
emerge in niches in the context of existing regime and landscape developments. There is not yet a dominant design, and there may be various technical forms competing with each other. Actors improvise, engage in experiments to work out the best design and find out what users want.

In the second phase the novelty is used in small market niches, which provide resources for technical specialisation. Gradually, a dedicated community of engineers and producers emerges, collectively directing their activities to the improvement of the new technology. Engineers gradually develop new rules, and the new technology develops a technical trajectory of its own. The new technology gradually improves, as a result of learning processes. As users interact with the new technology and incorporate them into their user practices, they gradually explore new functionalities. This second phase results in a stabilisation of rules, e.g., a dominant design, articulation of user preferences.

The third phase is characterised by a breakthrough of the new technology, wide diffusion and competition with the established regime. On the one hand, there are internal drivers for breakthrough, e.g., price/performance improvements, increasing returns to adoption, and actors with interests that push for further expansion of the technology. On the other hand, breakthrough depends on external circumstances and 'windows of opportunity' (see Fig. 4). The regime may come under pressure from changes at the landscape level or there may be internal technical problems in the regime, which cannot be met with the available technology. There may also be negative externalities in the regime, changing user preferences or stricter regulations, which create problems for the existing technology. The key point of the MLP is that system innovations occur as the outcome of linkages between developments at

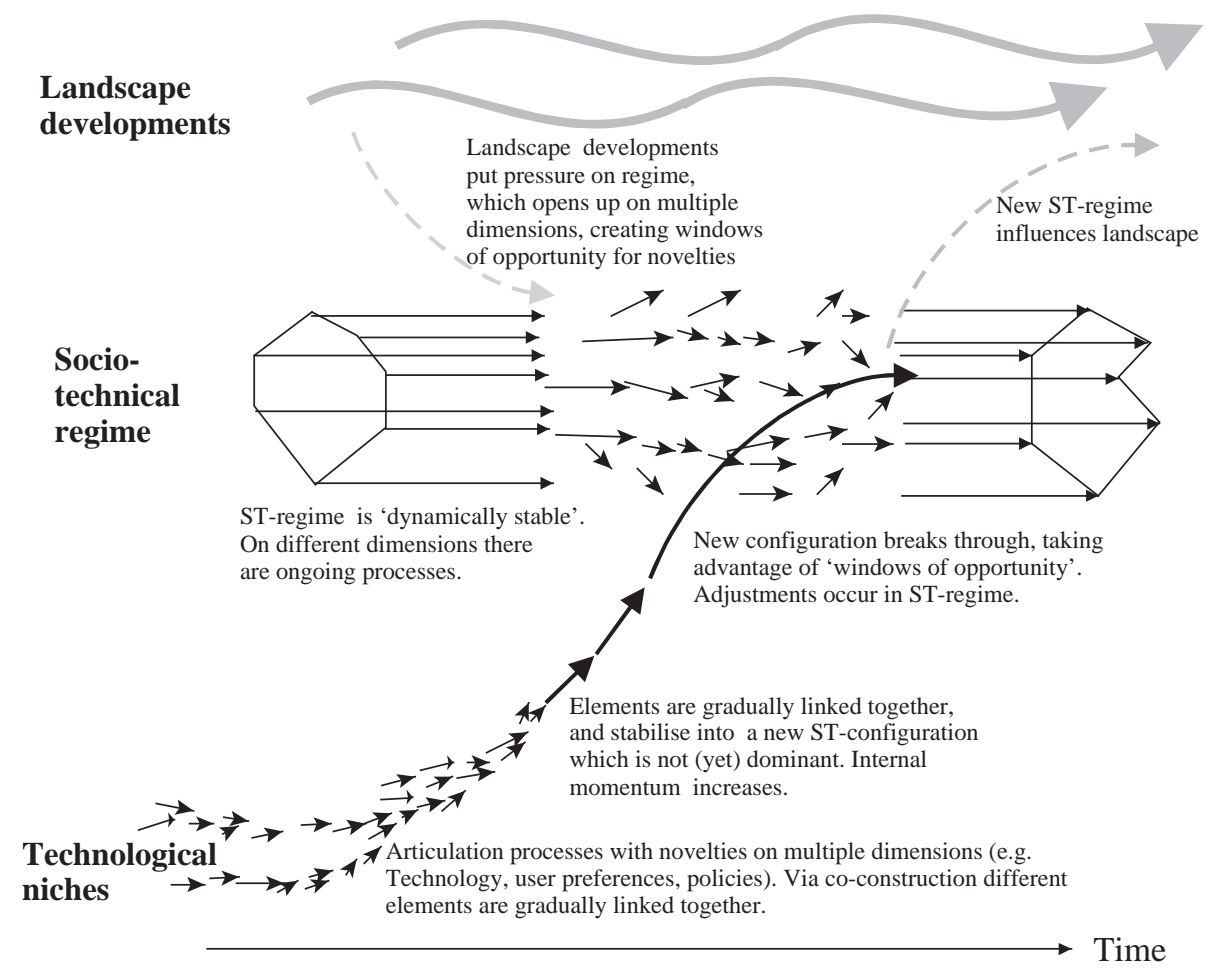

Fig. 4. A dynamic multi-level perspective on system innovations ([12], p. 1263). 
multiple levels. As the new technology enters mainstream markets, it enters a competitive relationship with the established regime.

In the fourth phase the new technology replaces the old regime, which is accompanied by changes on wider dimensions of the sociotechnical regime. This often happens in a gradual fashion, because the creation of a new sociotechnical regime takes time. Furthermore, incumbents tend to stick to old technologies, because of vested interests and sunk investments. The new regime may eventually influence wider landscape developments.

An important aspect of the MLP is to do away with simple causality in system innovations. There is no simple 'cause' or driver. Instead, there are processes at multiple dimensions and levels simultaneously. System innovations come about when these processes link up and reinforce each other ('circular causality').

\section{Patterns in system innovations}

Sociotechnical systems are complex and consist of linkages between several elements. Patterns can be found by making different cross sections, focusing on relationships between two or more elements.

\subsection{Routes in system innovations}

Based on the interplay between the three levels in the MLP, different routes can be distinguished in system innovations: (a) technological substitution, (b) wide transformation.

\subsubsection{Technological substitution route}

In the technological substitution route the existing sociotechnical regime is initially relatively stable, characterised by incremental developments. Radical innovations emerge in niches, 'below the surface', relatively 'hidden' for actors at the regime level. At the niche level, the novelty is gradually improved. Breakthrough of the novelty in mainstream markets may occur when the novelty has aqcuired enough internal momentum, and when landscape developments put pressure on the existing regime. The dynamic of long smouldering below the surface followed by sudden breakthrough may metaphorically be described as 'peat moor fire.' Because novelties are developed below the surface, established regime actors may be taken by surprise by their breakthrough in mainstream markets. This may lead to creative destruction and the downfall of established firms [18]. The breakthrough triggers all kinds of adaptations and transformations in the regime, leading to an 'era of ferment.' Hence, this route has a technologypush character. Once a new sociotechnical regime has been formed, the dynamic shifts back to incremental change (see Fig. 5).

An example is the transition from propeller-piston engine aircraft to turbojets in civil aviation (see [7] for an elaborate analysis). When turbojets emerged in the mid-1930s, the piston engine-propeller aircraft regime was stable. Although there were some minor problems (altitude problem and high-speed problem), the aviation community was convinced of the potential of piston engines and propellers to solve them (e.g., variable pitch propellers, supercharging). Because of the stability of the existing regime, jet engine pioneers had great difficulty to get interest and funding within the aeronautic community. The landscape development of the Second World War changed the selection environment and created a particular niche in which the turbojet could be developed: interceptor fighters. Their 
Landscape-level

Niche-level

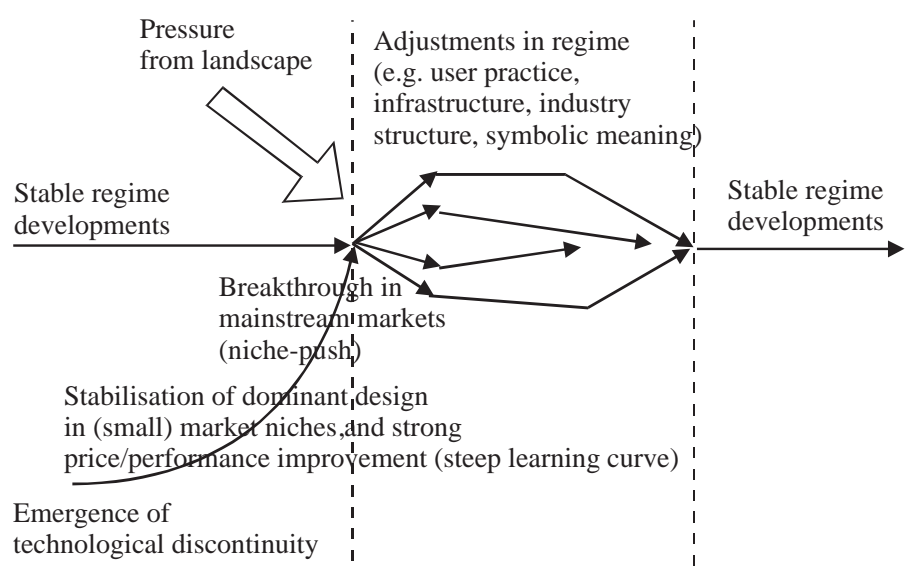

Fig. 5. Technological substitution route in system innovations.

performance by the end of the war (high speed, but also high fuel consumption) led to a change in the perception in the aeronautic community and a bandwagon effect. After the war, jet engines were further developed in the military domain. Meanwhile, in the domain of civil aviation the piston engine still reigned supreme. Large four-engine planes were developed and applied on ever-longer distances. It was not until the early 1950s that jet engines were taken seriously in civil aviation. The turbojet entered civil aviation in 1958 as part of strategic games between Boeing and Douglas Aircraft Company, in the longrange market niche (trans-Atlantic route). Despite low initial expectations, jet engines worked costefficiently. The engines needed less maintenance, because they had fewer moving parts. They were also more powerful and capable of propelling larger planes, enabling scale economies. Because jet planes were faster, they could be used more frequently per year, raising productivity. Hence, in the longdistance market, four-engine piston aircraft were rapidly replaced. As jetliners were down-scaled (e.g., the Boeing 727 in 1964) they also entered other market niches (shorter distances, fewer passengers). A new functionality was introduced in aviation as the introduction of jumbo jets (1969) changed flying from a luxury for businessmen to a transport mode for the masses. One of its wider societal impacts was the tremendous expansion of worldwide tourism. The introduction of jetliners in civil aviation led to a range of adaptations in the sociotechnical regime. The larger aircraft needed longer runways, pilots required new skills, maintenance procedures were adapted, tariffs were lowered, airline companies searched for new user groups, and adaptations were made in air traffic control (radar and computers).

\subsubsection{Wider transformation route}

In the transformation route the regime becomes unstable and opens up in an early phase, because of persistent problems or landscape changes. Simultaneous changes occur on multiple regime dimensions, e.g., policy, user preference, technology, infrastructure, culture, etc. The loosening up of the existing regime stimulates actors to experiment with other technical options. There is a prolonged period of experimentation, and strategic maneuvering. Such a period of heating up is eventually followed by a period of 'cooling down,' i.e., narrowing down the number of technical options. A particular technical option may come to be seen as 'universal,' push other options out of the market and acquire dominance. This is complemented by the creation of a new sociotechnical regime (see Fig. 6). The cycles at the regime level highlight the substantial flux, uncertainty and interactions between multiple technologies. 


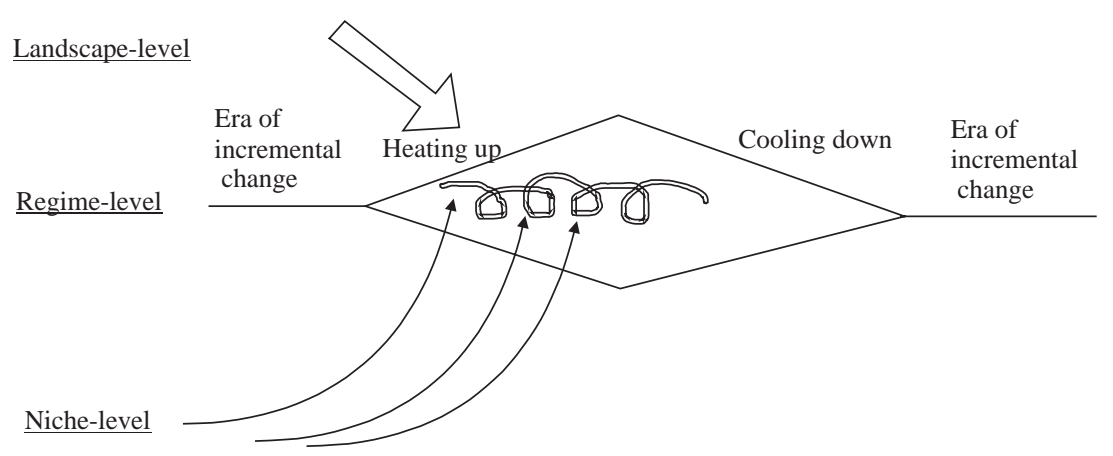

Fig. 6. Wider transformation route in system innovations.

An example is the transition from horse-drawn carriages to automobiles in America (see [7] for an elaborate analysis). The urban horse-based transportation regime was heating up in the late 19th century, before the emergence of automobiles. The regime suffered from several problems: congestion, pollution from horse-droppings, lack of safety, high cost (horse tram companies had large stables with thousands of horses that required care and food). These problems were made worse by landscape developments. Immigration led to the emergence of slums, where filth and disease accumulated. The rising concern about public health at the end of the 19th century led to debates about horse excrements on streets. Urbanisation and sub-urbanisation led to larger cities and longer travel distances, which were hard to meet with horse-based transportation.

In the 1880s and $1890 \mathrm{~s}$, new transport options emerged, e.g., steam tram, electric tram, bicycle, steam automobiles, electric automobiles, gasoline automobiles. Some of these innovations stimulated wider changes in the sociotechnical regime (acting as catalyst, see Section 3.2). The bicycle led to the articulation of the new user preferences for individual and flexible transport. The bicycle also opened new application domains: touring (in the countryside) and racing. In that sense the bicycle contributed to new mobility practices: touring for fun. In social and infrastructural dimensions the bicycle gave rise to the creation of a Good Roads movement, which lobbied politicians for streets with smoother surfaces (e.g., asphalt). The bicycle gave rise to traffic regulation, and to many bicycle clubs and bicycle papers, periodicals, etc. Some of the bicycle regulations were later applied to automobiles. The electric tram stimulated a change in perception of the function of streets. Before 1890 many streets still fulfilled 'traditional' functions as social meeting places. With the trolley, streets came to be seen as transport arteries. A second cultural change was the experience of speed. City residents gradually became used to higher speeds of vehicles. In the 1890s the electric tram allowed middle classes to move to suburbs, expanding the mobility practice of commuting. The automobile linked up with many of these regime changes in the early 20 th century.

In the early 20th century the electric tram became the dominant urban transport system. Automobiles played minor roles in particular niches. Electric vehicles emerged in the niche of taxis and luxury vehicles, used for tea parties, or promenading in parks and boulevards. Internal combustion engine vehicles were first used for racing and touring. Steam automobiles were also used to some extent in racing and touring, but they were heavy and needed time to generate steam. The niches of racing and touring grew rapidly in the early 20th century, because they linked up with new cultural values. These new values were related to landscape developments such as the rise in real wages, and the emergence of a new middle class with more money and leisure time, preferably enjoyed in the form of entertainment. 
A new popular culture emerged, focused on entertainment, adventure, outdoor activities. In this context, the niches of car racing and touring in the countryside became very popular. Hence, the sales of gasoline automobiles raced ahead, while those of electric vehicles and steam automobiles remained constant. In 1908, the T-Ford emerged as a dominant design. In the 1910s, the countryside provided a major market niche for the T-Ford. As the price of the Model T went down (from $\$ 850$ in 1908 to $\$ 360$ in 1916), it was increasingly used by middle class urbanites for commuting. In the 1920s, the car became an all-purpose road cruiser, which began to challenge the electric tram as the dominant urban transport technology.

The competition between the automobile and the electric tram in the 1920s and 1930s was strongly influenced by political choices. Policy makers helped to construct a car-based transportation system by widening existing roads and creating new roads. During the 1930s, the car (and the bus) began to replace the electric tram as the dominant urban transport system. A major impact of the car was the transformation of the city, in particular sub-urbanisation, more roads, new function of the street, traffic regulations, and segregation of public space. The automobile also contributed to major transformations of rural areas, e.g., the disappearance of schools, churches, small shops and medical facilities from small villages.

\subsection{Fit-stretch pattern in the co-evolution of form and function}

The second pattern in system innovations is that the co-evolution between technical form and (social) function follows a fit-stretch pattern. In the early phase of a transition, both form and function of new technologies have a close fit with the existing regime. The function of new technologies is often interpreted with categories associated with the existing regime. Gradually, technical developments lead to new technical forms and concrete user experience leads to new functionalities (stretch pattern). This fit-stretch pattern is schematically represented in Fig. 7.

The fit-stretch pattern is illustrated with the example of the automobile transition (summarised in Table 1). The early builders of automobiles saw the technology as a 'horseless carriage' (fit). This was also represented in the form of early automobiles, which in the 1880s and 1890s were existing carriages or tricycles fitted with an additional power source (battery and electric motor, gasoline engine, steam

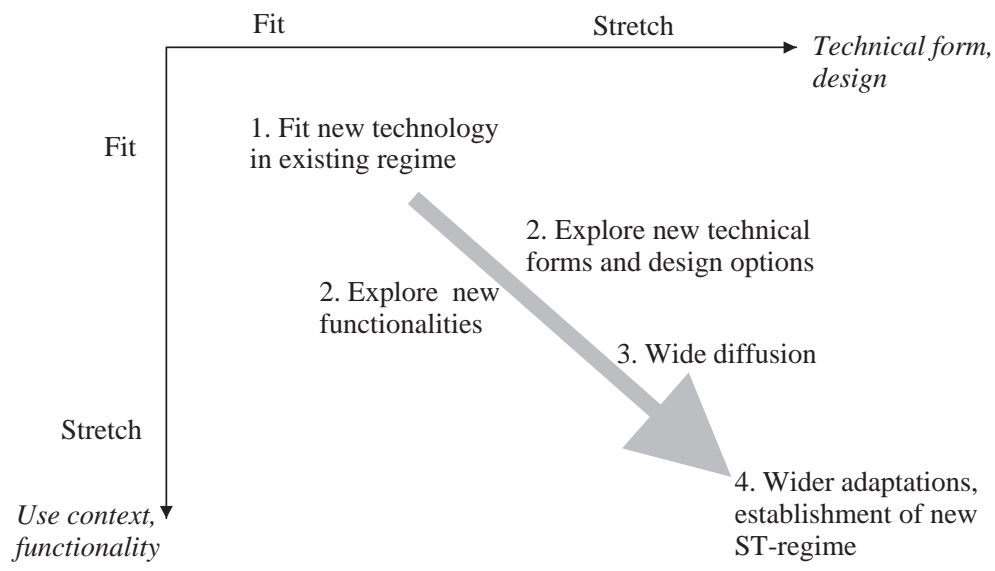

Fig. 7. Fit-stretch pattern in the co-evolution of form and function. 
Table 1

Fit-stretch pattern in the co-evolution of form and function in the automobile transition

\begin{tabular}{|c|c|c|}
\hline $\begin{array}{l}\text { Technical form } \\
\text { use environment }\end{array}$ & Fit & Stretch \\
\hline \multirow[t]{2}{*}{ Fit } & $\begin{array}{l}\text { Early automobiles consisted of existing } \\
\text { carriages or tricycles with additional power } \\
\text { sources. Electric vehicles were used as taxi } \\
\text { and as substitute for luxury horse-and-carriage } \\
\text { (tea parties, promenading). Gasoline cars were } \\
\text { defined as 'adventure' machines and were } \\
\text { used in races and touring. }\end{array}$ & $\begin{array}{l}\text { In the context of races and touring, } \\
\text { the gasoline car developed a specific } \\
\text { form, which deviated from existing } \\
\text { carriages: lower, wider, with 'nose' } \\
\text { (the hood). }\end{array}$ \\
\hline & & $\begin{array}{l}\text { In America, touring became very } \\
\text { popular (mobility for fun), exploiting } \\
\text { the new functionalities of private, } \\
\text { flexible transport. }\end{array}$ \\
\hline Stretch & & $\begin{array}{l}\text { After } 1905 \text {, the gasoline automobile } \\
\text { was used for business purposes. } \\
\text { The T-Ford (1908) was the new } \\
\text { dominant design: a cheap, robust } \\
\text { car for practical use. Scale effects } \\
\text { and mass production drove the price } \\
\text { down, stimulating wider diffusion. } \\
\text { Diffusion was accompanied by } \\
\text { changes in infrastructures, traffic } \\
\text { rules, pedestrian routines, mobility } \\
\text { patterns. }\end{array}$ \\
\hline
\end{tabular}

engine). In the 1890 s and in the context of racing and touring, gasoline cars developed a characteristic form of their own, with a nose on the front, lower and wider. In racing and touring, the new functionalities of cars were celebrated: private and flexible transport at high speed (in contrast to horsetrams and electric trams which were public and followed fixed routes). These mobility practices also articulated the functional dimension of fun. The form and function of electric vehicles, on the other hand, remained close to the existing coaches. The precise market niche of steam automobiles remained unclear, also because their manufacturers were more interested in making beautiful machines, than in market articulation. Around 1905, gasoline cars also came to be used for more practical and business purposes (e.g., doctors, salesmen, rich farmers, taxi drivers). The T-Ford provided a cheap yet robust car, which enhanced the practical use, enabling the diffusion to the large rural market. Cars were also increasingly used by middle classes for commuting between work and home. This way the car linked up with the trend towards sub-urbanization. The diffusion was accompanied by wider transformations in the city.

\subsection{Patterns in the breakthrough from niche to regime level}

The crucial step in system innovation takes place when innovations break out of niches and enter mainstream markets, where they compete with existing technologies and trigger wider changes in the sociotechnical regime. The MLP argues that breakthrough and wide diffusion depend on linkages with ongoing processes at the regime and landscape level. But the MLP also acknowledges that internal 
drivers are important. A well-known economic driver is price/performance improvement. But there are also sociotechnical and social drivers, something which is underaddressed in the innovation literature. The article makes contributions on this point, distinguishing three kinds of patterns in the breakthrough from niche to regime level: (a) niche accumulation, (b) co-evolution of technologies, and (c) actorrelated patterns.

\subsubsection{The pattern of niche accumulation}

The step from niche to regime level does not occur at once, but gradually and in subsequent steps, as a new technology 'branches' or 'penetrates' different application domains. Following Levinthal [19] and Schot [14], it is proposed that the diffusion of radical innovations follows trajectories of niche accumulation. A novelty is first developed in a particular technological niche or a specialised market niche. Further diffusion occurs as radical innovations are used in subsequent application domains or market niches, i.e., an accumulation of niches. Fig. 8 gives an example of the diffusion of automobiles in terms of niche accumulation.

\subsubsection{Co-evolution of technologies}

An important pattern in the breakthrough of innovations from the niche level is formed by linkages between multiple technologies. Several authors [20-22] argue for the importance of interlocking,

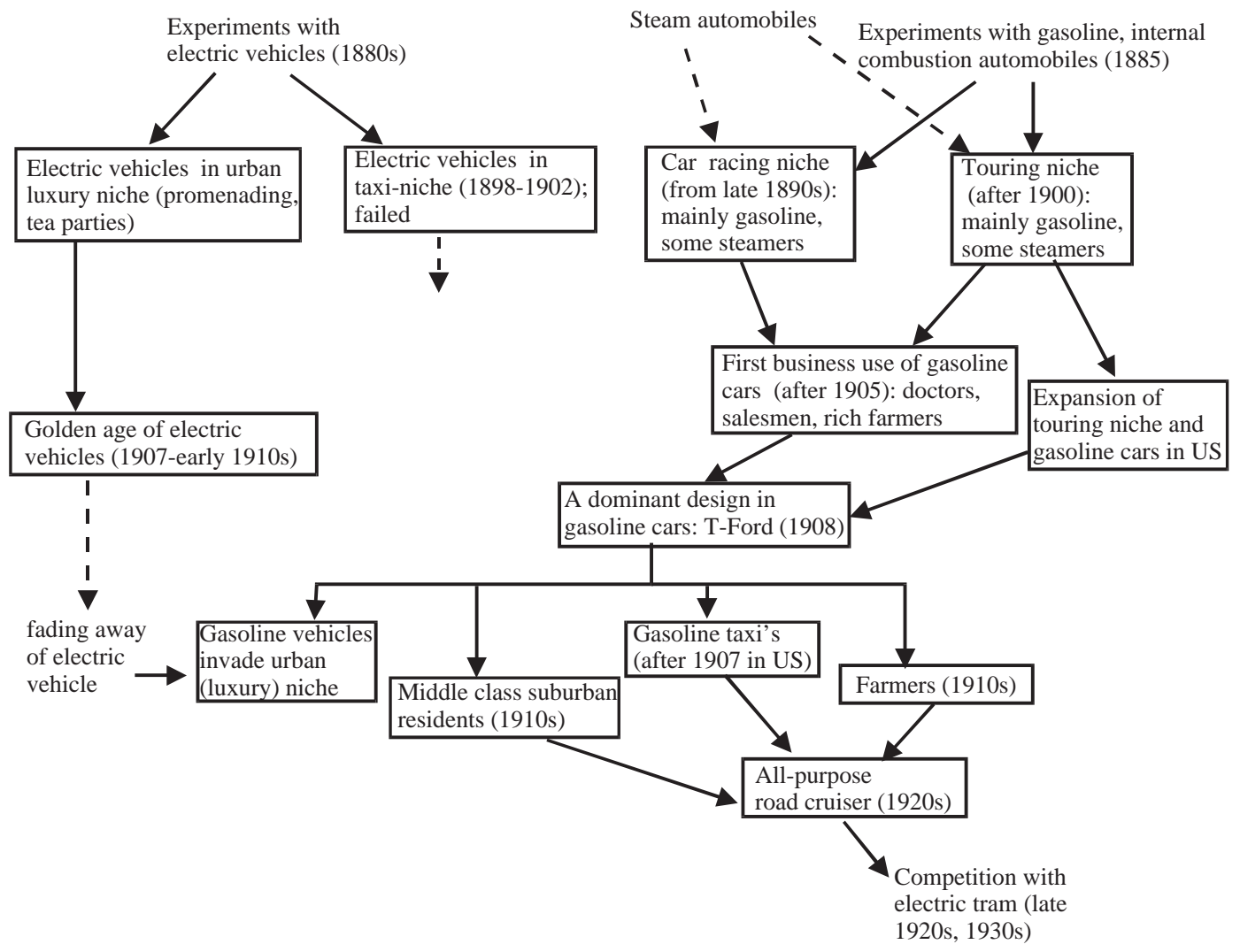

Fig. 8. Trajectory of niche accumulation for automobiles. 
alignment and positive feedback between multiple technologies in generating momentum. "Compatibility, inter-relatedness and co-development are emerging as important themes in modern diffusion research. Furthermore, the single innovation is no more seen as the appropriate unit for diffusion analysis. (...) A multi-technology approach is called for" ([23], p. 107). While co-evolution of technologies is a general pattern in system innovations, different kinds of specific interactions between technologies can be distinguished.

A well-known form of interlocking is complementarities between technologies. When the functionality of a new technology is hampered by particular constraints and problems, the linkage with another technology may solve them and boost performance and diffusion. An example is the complementarity between screw propellers and iron hulls in steamships. Early steamships used paddlewheels and were made of wood. When screw propellers began to replace paddlewheels in the 1840 s, this led to the vibration problem. The higher rotational speed of steam engines and screw propellers almost shook the wooden steamships apart. Iron hulls solved this problem, because it was a stronger material.

Interactions that are often important in system innovations are technical add-on and hybridization. Old and new technologies need not always compete from the start, but can form some sort of symbiosis. For instance, gas turbines (the basic component of turbojets) entered propeller aircraft as supercharging devices in the 1920s to help them fly at high altitudes in thin air. Another example is that steam engines entered sailing ships as an auxiliary device to be used for specific problems, e.g., if there are no winds. In the 1840 s and 1850 s, hybrid ships were built where sail and steam were equally important propulsive mechanisms.

Another interaction is sequential accumulation, in which the first new technology acts as a 'catalyst' in the sense of opening up the existing regime [24]. This then provides opportunities for a later technology to link up with. An example is the role of the bicycle in the transition from horse-drawn carriages to automobiles (described above). The bicycle led to change processes in the sociotechnical regime on which the automobile could later build.

A fourth kind of multi-technology interaction is that competing technical trajectories may 'borrow' technical elements from each other. For instance, the gasoline car 'borrowed' batteries and high voltage ignition from the electric vehicle, leading to the electric starter, which made it much easier to start gasoline cars (which previously had to be crank-started).

\subsubsection{Actor-related patterns}

The MLP can be characterised as a process approach. The explanation of the emergence of new regimes is that multiple developments gradually link up and reinforce each other. Although processes at different levels can converge and create windows of opportunity for regime change, the actual linkages always need to be made by actors. Hence, the MLP needs to be filled in with more detailed actor-related patterns. The increasing support and involvement of actors is important to get the bandwagon going and stimulate diffusion and breakthrough. The involvement of actors makes diffusion a non-linear process with accelerations and slowing down. This is the result of sometimes rapid shifts in perceptions, 'moods' and strategic interactions. In case studies, these shifts can be analysed in detail, looking at micro-activities in local practices. But there do exist somewhat more generic patterns in social interactions. Such actor-related patterns are important building blocks to understand accelerations and slowing down in diffusion and breakthrough. The collection of actor-related patterns below is a first step in that direction. More systematic research is needed on this topic. The patterns are grouped with regard to particular actors. 


\subsection{Firm-related patterns}

1. Innovation races and strategic games can play a role in the acceleration of diffusion. For instance, Boeing and Douglas were involved in a strategic game with regard to civil jetliners in the 1950s. Douglas chose a wait-and-see strategy, letting Boeing carry the first-mover risk in developing jetliners. When Boeing's efforts seemed to become productive, Douglas followed quickly, leading to an acceleration in the development path.

2. Saturation of existing markets and sales crises form a stimulus for firms to diversify to other markets and technologies. For instance, the bicycle crisis of 1898 stimulated bicycle producers to diversify into automobiles, leading to new entries in the emerging automobile sector, and an acceleration of development. Another example is that the market for long-range strategic bombers was expected to shrink in the 1950s, as strategic missiles emerged as a military option for strategic bombardment. This created pressure on Boeing, who had become a large company in the production of bombers. Hence, Boeing aimed to diversify into civil aviation, where the company was a relative outsider compared to Douglas Aircraft. To enter the civil aviation market, Boeing adopted a leapfrog strategy, aiming to be the first to develop jetliners. This accelerated the entry of jet engines in civil aviation.

3. When incumbent firms are threatened by new technologies, they may try to defend themselves by improving the existing technology. This is called the 'sailing ship effect' [25]. When steamships challenged sailing ships in the 1860 s and 1870 s, many improvements were made in sailing ships. To increase their speed, more masts and sail were added. To reduce labour costs, labour-saving machines were introduced, e.g., to rig the sails. The improvement in incumbent technologies may delay the wide diffusion of new technologies.

4. 'Missing the wave' means that incumbent companies are too late in recognising the potential of newly emerging technologies [26]. They may be 'blind' to innovations, which emerge in small niches, or they may hold on (too long) to the old technology, trying to improve it and fight off newcomers. This is an important reason behind the process of creative destruction and the downfall of established firms. An example is that most established shipbuilders did not make the shift from wood and sail to iron and steam, which required new skills (e.g., riveting and metal working) and new machine tools. These established wood and sail shipbuilders (gradually) disappeared from the market.

5. Incumbent firms and old technologies may hold on in particular market niches for a long time, even after the new technology has become dominant. This can be a useful transition pattern, as it helps to reduce social unrest, because actors associated with the old regime do not immediately lose their jobs. Although steamships broke through in the 1870 s and 1880 s, sailing ships continued to be used in bulk freight markets (e.g., iron, coal, rice, wool) well into the 20th century.

6. Incumbent firms and old technologies may evade to other market niches when they are replaced in mainstream markets. This also helps to ease the pain of a transition. When jet aircraft replaced passenger steamships in the $1950 \mathrm{~s}$, the latter evaded to the market of cruises.

\subsection{User- and culture-related patterns}

7. A 'cartel of fear' may slow down diffusion. For instance, American airline companies long hesitated to buy jetliners, because there were many uncertainties about their performance (in particular fuel costs). No airline company one wanted to take the first step, because of the risks involved. So long as no airline company introduced jets in the American market, no one needed to buy it. The shared fear 
led to inertia. Firms watched each other, but no one acted. This situation can turn into rapid acceleration, when one of the actors makes a move, and breaks the deadlock. When Pan Am ordered jets in 1954, other airline companies quickly followed, for fear of being left behind. This led to a domino effect and rapidly increasing orders for jetliners.

8. When new technologies link up with wide cultural visions and values, this creates a legitimation and a protected (cultural) space to work on new technologies [27]. Aircraft in the 1920s and 1930s enjoyed great popular support, because they were seen as means to a better world, the winged gospel [28]. Similar cultural visions (of a better world or a new economy) were also developed with regard to the Internet. As long as these visions last, they attract resources and entrepreneurs for the development of new technologies.

9. Hypes and bandwagon effects on the demand side can play a role in the take-off of new technologies. The diffusion of safety bicycles benefited from the bicycle craze (1895-1897), when middle class consumers bought bicycles to tour in the countryside. A recent example, of course, is formed by the hype around the Internet and UMTS (third-generation mobile telephony). But when expectations are hyped too much, they may be followed by a backlash. After the bicycle craze, the global bicycle market collapsed in 1898, leading to overproduction and price dumping. The Internet and UMTS hype were also followed by a backlash.

\subsection{Policy-related patterns}

10. Policy support is often important for the diffusion of new technologies. For instance, national governments gave tremendous financial support to airline companies in the 1920s and 1930s and stimulated aviation through sponsoring of research (aerodynamic, fuels, engines). This was possible, because of societal support and cultural enthusiasm about aviation.

11. The political stimulation of new technology can be part of wider power struggles, leading to accelerations or delay. In the early 20th century, American electric tram companies had a monopoly on urban mass transport and antagonistic relationships with city governments. When the automobile became a practical transport option in the 1920s and 1930s, city governments massively subsidised car transport through construction and improvement of roads. This was partly a response to demands from middle-class constituencies, but also a move to undermine the strength of electric tram companies [29].

\section{Discussion and conclusions}

This paper has described a multi-level perspective which provides an overall framework to understand system innovations. System innovations involve simultaneous processes on multiple dimensions and levels. They are a blend of longer term and shorter term processes. System innovations require that these processes link up and reinforce each other. Subsequently, the overall perspective was further refined by distinguishing co-evolutionary and sociotechnical patterns in system innovations: (a) two transition routes, (b) a fit-stretch pattern, and (c) patterns in breakthrough. The analytical step towards patterns is important, not just because they form building blocks in understanding system innovations. The MLP can be characterised as working 'from the outside in,' describing, mapping and analysing the entire longterm process. The explanation of the emergence of new regimes is that multiple developments gradually 
link up and reinforce each other. Actors and agency thus disappear from view, although it is evident that they play a crucial role. Especially the actor-related patterns in breakthrough form a way to introduce actors and their activities into the framework. The structuralist analysis is thus filled in with agency. The 'outside-in' approach is complemented with another approach, which works 'from the inside out' focussing on actors and their interactions. Actor-related patterns thus form an important link between outside-in and inside-out perspectives on system innovation.

\section{Acknowledgements}

I thank Anna Wieczorek, Boelie Elzen and two anonymous referees for their useful comments on earlier versions of this article.

\section{References}

[1] Geels, 2004, Geels, F.W.: From Sectoral Systems of Innovation to Socio-Technical Systems: Insights about Dynamics and Change from Sociology and Institutional Theory, Research Policy, 33 (5) (in press).

[2] F. Berkhout, Technological regimes, path dependency and the environment, Global Environmental Change 12 (2002) 1-4.

[3] G.C. Unruh, Understanding carbon lock-in, Energy Policy 28 (2000) 817-830.

[4] S. Jacobbson, A. Johnson, The diffusion of renewable energy technology: an analytical framework and key issues for research, Energy Policy 28 (2000) 625-640.

[5] B. Elzen, F.W. Geels, K. Green (Eds.), System Innovation and the Transition to Sustainability: Theory, Evidence and Policy, Edward Elgar, Cheltenham, 2004.

[6] F. Malerba, Sectoral systems of innovation, Research Policy 31 (2) (2002) 247-264.

[7] F.W. Geels, Technological Transitions and System Innovations: A Co-evolutionary and Sociotechnical Analysis, Edward Elgar, Cheltenham, 2005.

[8] R. Kemp, Technology and the transition to environmental sustainability. The problem of technological regime shifts, Futures 26 (1994) $1023-1046$.

[9] J. Schot, R. Hoogma, B. Elzen, Strategies for shifting technological systems: the case of the automobile system, Futures 26 (1994) $1060-1076$.

[10] A. Rip, R. Kemp, in: S. Rayner, E.L. Malone (Eds.), Technological, Change, in Human Choice and Climate Change, Battelle Press, Columbus, OH, 1998, pp. 327-399.

[11] R. Kemp, J. Schot, R. Hoogma, Regime shifts to sustainability through processes of niche formation: the approach of strategic Niche management, Technology Analysis and Strategic Management 10 (1998) 175-196.

[12] F.W. Geels, Technological transitions as evolutionary reconfiguration processes: a multi-level perspective and a case study, Research Policy 31 (8/9) (2002) 1257-1274.

[13] R.R. Nelson, S.G. Winter, An Evolutionary Theory of Economic Change, Bellknap Press, Cambridge, MA, 1982.

[14] J.W. Schot, The usefulness of evolutionary models for explaining innovation. The case of the Netherlands in the nineteenth century, History of Technology 14 (1998) 173-200.

[15] R. Kemp, A. Rip, J. Schot, Constructing transition paths through the management of Niches, in: R. Garud, P. Karnoe (Eds.), Path Dependence and Creation, Lawrence Erlbaum Associates, Mahwah, NJ, 2001, pp. 269-299.

[16] R. Hoogma, R. Kemp, J. Schot, B. Truffer, Experimenting for Sustainable Transport: The Approach of Strategic Niche Management, Spon Press, London, 2002.

[17] J. Rotmans, R. Kemp, M. Van Asselt, More evolution than revolution: transition management in public policy, Foresight 3 (1) (2001) $15-31$.

[18] C. Christensen, The Innovator's Dilemma: When New Technologies Cause Great Firms to Fail, Harvard Business School Press, Boston, MA, 1997.

[19] D.A. Levinthal, The slow pace of rapid technological change: gradualism and punctuation in technological change, Industrial and Corporate Change 7 (1998) 217-247. 
[20] N. Rosenberg, Inside the Black Box: Technology and Economics, Cambridge University Press, Cambridge, 1982.

[21] R.U. Ayres, Technological Transformations and Long Waves, Research Report-89-1, IASSA, Laxenburg, 1989.

[22] A. Grübler, N. Nakićenović, Long Waves, Technology Diffusion, and Substitution, Research Report-91-17, IIASA, Laxenburg, 1991.

[23] F. Lissoni, J.S. Metcalfe, Diffusion of innovation ancient and modern: a review of the main themes, in: M. Dodgson (Ed.), The Handbook of Industrial Innovation, Edward Elgar, Cheltenham, UK, 1994, pp. 106-141.

[24] K.H. Sørensen, Social Shaping on the Move? On the Policy Relevance of the Social Shaping of Technology Perspective, in: K.H. Sørensen, R. Williams (Eds.), Shaping Technology, Guiding Policy: Concepts, Spaces and Tools, Edward Elgar, Cheltenham, UK, 2002, pp. 19-35.

[25] W.H. Ward, The sailing ship effect, Bulletin of the Institute of Physics and Physical Society 18 (1967) 169.

[26] J.L. Bower, C.M. Christensen, Disruptive technologies: catching the wave, Harvard Business Review (1995 JanuaryFebruary) $43-53$.

[27] H. Van Lente, Promising Technology: The Dynamics of Expectations in Technological Development, PhD thesis Twente University, Eburon, Delft, 1993.

[28] J.J. Corn, The Winged Gospel: America's Romance with Aviation, 1900-1950, Oxford University Press, New York, 1983.

[29] Z.M. Schrag, The bus is young and honest: transportation politics, technical choice, and the motorization of Manhattan surface transit, 1919-1936, Technology and Culture 41 (2000) 51-79.

Dr. Frank Geels is post-doctoral researcher at the Department of Technology Management, at Eindhoven University of Technology, the Netherlands. His main research topics are technological transitions and system innovations. He has approached these topics in several ways, e.g., through theory development, using insights from sociology of technology, innovation studies and evolutionary economics. The conceptual work is grounded in thorough historical case studies on transitions in the past. He has also explored possible future transitions in transport and energy, using socio-technical scenarios as new exploration methodology. 